\title{
A Statistical Methodology for Impact Study on Irrigation Tank Rehabilitation
}

\author{
B. Anuradha†, L. Iyappan, P. Partheeban, C. Hariharasudan and Y.J. Breetha \\ Department of Civil Engineering, Chennai Institute of Technology, Chennai, Tamil Nadu, India \\ $\dagger$ Corresponding author: B. Anuradha; anu_bas2003@yahoo.com
}

Nat. Env. \& Poll. Tech. Website: www.neptjournal.com

Received: 03-06-2020

Revised: $07-08-2020$

Accepted: $27-08-2020$

\section{Key Words:}

Tank rehabilitation

Irrigation management

Cropping pattern

Irrigation intensity

\begin{abstract}
Tank systems are essential for the agricultural growth and the livelihood of rural populations in India. Comprehending the multiple benefits from these traditional systems, tank rehabilitation has been one of the policy significances at the state level. The study was undertaken with the objective of assessing the impact of tank rehabilitation on cropped area, cropping pattern change, cost returns and income of farmers in a selected study village of south Tamil Nadu. The study was conducted on the basis of primary data obtained from 102 sample farmers belonging to "Pelasur" village of Thiruvannamalai district in south Tamil Nadu using a stratified sampling method. There was a significant difference in the cropped area, cropping intensity and irrigation intensity among the farmers before and after tank rehabilitation. It is found that there is an increase of 41.02 ha cultivated area and an increase in the net amount of Rs. 7,99,945. Many farmers shifted from paddy to sugarcane (cash crops) cultivation due to the availability of excess surface water in the tank and improved water table in their wells. Cropping intensity has been increased to $26 \%$ in the post-rehabilitation period. Thus, investment in tank rehabilitation shows a positive implication on marginal farmers and landless labours. Using SPSS, a paired-sample t-test is applied for analysing data collected from respondents.
\end{abstract}

\section{INTRODUCTION}

India is experiencing a wide variety of climate in its 329 Mha total geographic area. Out of which 143Mha is under cultivation which supports $40 \%$ of the population (Vaidyanathan 2006). In order to meet out the abovementioned support, 108Mha is under rainfed agriculture and the remaining area depend on conserved water in various storage structure like dams, reservoir, tanks etc. (Sengupta 1985, Shah 2009, Jana et al. 2012, Sowbi \& Sabarish 2017). Southern states of India like Tamil Nadu, Karnataka, and Andra Pradesh widely depends on tank irrigation for agricultural activities. As per government records, there are $1,43,000$ numbers of tanks existing altogether in the abovementioned states which include 39000 tanks in Tamil Nadu alone (Sakthivadivel 2005). These structures were made by our ancestor some decades ago to meet out the multiple needs of local village people and also maintained by the local body (Vaidyanathan 2006, Narayanamoorthy 2007). The tank receives water in the form of runoff from its own catchment during rainfall with respect to the terrain. This conserved water is released through the sluice for irrigation purpose with the help of shutters provided for flow control. Water reaches the field by gravity since tanks are located in the upper level and field in the lower level (Shah \& Raju 2001). Three to four sluice are in the tank bed depending upon the size and capacity of the tank. Each field channel from the sluice is divided into head, middle and tail reach of the command area. The local village landholders distribute water for irrigation among themselves in an equitable manner (Meinzen-Dick 2007, Persha et al. 2011, Fischer et al. 2014, Jagger et al. 2018). The periodical tank management was increasingly neglected in due course might be the strong reason behind the dysfunctional of irrigation tank component structures in terms of silting tank bed, supply channel and weed infestation results in the reduction of the storage capacity of the tank. Tank bunds became weaker in nature which results in leakage and breaches. Considering the degradation rate, few tanks were selected and planned to rehabilitate for regaining their design standard (MeinzenDick 2007, Aubriot \& Prabhakar 2011, Kiran Kumara 2018). With the context of farmers, participation and management tank were rejuvenated for improving their performance level. Tank rehabilitation should facilitate more augmentation of water, strengthening tank bund in order to protect it from flood damage, improvise water storage capacity, magnifying availability of water for irrigation, promotes conjunctive use of surface and groundwater, reduce tank bed filtration, increase crop cultivation, facilitates groundwater recharge, increase the reliability of fishing in tank dead storage during the summer season, provide additional income through tank bund rehabilitation, or short-duration crops grown in tank bed during the dry season and should provide sustainable benefits to the users (Chiranjeevalu 1988, Govindaiah 1992, 
Easter 1997, Chattopadhyaya 2003, Agarwal \& Narain 2004, Singh et al. 2004, Sivasubramaniam 2006, Palanisamy \& Easter 2010, Balamurugan 2013). These water storage structures saved natural resources which enhance biomass production, manage the problems of drought, increase the ground water table, employment generation and elevate the socio-economic conditions of the tank users (Anuradha \& Ambujam 2011, Shah \& Sakthivadivel 2018).

\section{MATERIALS AND METHODS}

The research has devised a combination of qualitative and quantitative methodology in which primary and secondary sources are very thoughtfully tapped for information and perspectives. The focus of the contemporary study is to examine the impact of tank rehabilitation before and after on landholding and landless people in the rural tank. Hence, tank owning various livelihood options were selected to conduct interviews with landholders and focus group discussions with landless people. Since the study emphasises the improvements in livelihood options for direct and indirect users of the tank, data were collected for pre and postrehabilitation periods in the study area.

The data collected through the interview schedule was properly coded, master tabulated and analysed using the Statistical Package for Social Science (SPSS). Details collected through focus group discussion were documented in order to describe the developments experienced by users in the post-rehabilitation period. The methodology adopted in the present study that is discussed under the following subheads: Operational definition, Field setting, Respondents, Sampling framework, Sources of data, Data collection tools, Data analyses and Limitations. The operational definitions of various terms involved here in this study are presented, which may be trivial but are necessary for clarity of understanding. Irrigation: Irrigation is defined as the totality of means employed by farmers to augment and control the supply of water to soil for the purpose of production of crops (Adams 1989). Tank Rehabilitation: Tank rehabilitation is defined as restoring the tank components to their original design standards and to facilitate efficient water management and improved cropping practices and thereby providing better livelihoods for both direct and indirect tank users (Sakthivadivel et al. 2006, Anuradha 2008, Khandker et al. 2020, Naru \& Jana 2017). Livelihood: Livelihood comprises people, their capability and their means of living including food, income and assets (Shah 1998, Dharmasena 2019).

Pelasur tank located in a rural area of Thiruvannamalai district, Tamil Nadu, India was selected for this study and the tank was rehabilitated with huge amounts funded by the European Economic Community. Since this study vastly concentrates on other livelihood options related to the tank water, it was necessary to select the village which possesses more tank-based livelihood options including agriculture. After selecting the tank, the command area was divided into three segments representing head, middle and tail reaches. Later with the help of village Adangal records, farming households were identified and listed, which constitute the population frame for the study. Also, other indirect tank water users and the landless group were identified to conduct a discussion for getting relevant information on multiple tank uses for livelihood improvement. As stated earlier, the aim of the current study is to survey the impact of before and after tank rehabilitation conditions on landholding and landless group. Households of both the gender (women and men farmers) that has possessed a minimum one acre of land under the Pelasur tank command area was taken into consideration. Respondents from the above-mentioned households were selected by a stratified method. The landless population is grouped with respect to their livelihood occupations and the entire group was taken into consideration while selecting the respondents for conducting focus group discussion (Welgama \& Wanigasunder 2012).

Probability sampling can significantly enhance the descriptive sample. There are many types of probability samples that are likely to be encountered but this study was proposed to use a stratified sampling because it lends an extra component of accuracy to a simple random or systematic sample. The benefit of stratified sampling is that it incredibly improves the chance of proper representative of strata in the sample. At least two stratifying criteria can be utilized as a pair. The present study is stratified based on four strata. Before going in for stratifying the family households, the list of farming households in the study villages was collected from Adangal register maintained by the respective Village Administrative Officers (VAO). The Adangal is the source for the Government revenue and contains basic statistical information.

The impact of tank rehabilitation being the focus of the study, stratification with sampling unit i.e. households was felt necessary. Hence, while selecting a stratified sampling, the households were divided into different strata i.e. land holding, reach, farmers category and well-owning status. At the primary phase of stratification, the population was stratified by the model of landholding, in which two strata, landholding and landless gatherings were created At the primary phase of stratification, the populace was stratified. Landholding and landless households refer to households with land size greater than or equal to 50 cents and less than 50 cents correspondingly. At the second phase of stratification, the first stage of landholding farmers has been subdivided into head, middle and tail reach depending upon the location of 
the land. At the third stage, the respective second stage has been subdivided into marginal, small and other category of farmers reliant on the extent of respondents landholding. The classification of farmers, according to the Tamil Nadu Government, fall under a broad category of marginal, small, semi-medium, medium and large farmers. The statistics of the Tamil Nadu Government (2006) show that there are 72\% of marginal farmers followed by the small farmers, medium, semi-medium and large farmers constituting 17\%, 7.7\%, $2.8 \%$ and $0.5 \%$ respectively. Since the last three categories are small compared to the first two, the main focus of the study was concentrated on marginal and small farmers. However, the above three categories have been coalesced to form other farmers category. The same pattern of categorisation has been adopted by many irrigation management related projects. One such adaptation was followed in the Base Line Survey of Irrigation Commands, a Tamil Nadu Water Resources Consolidation Projects study undertaken by the Centre for Water Resources, Anna University, during the year 2000 and (Sophia \& Anuradha 2005). A similar example of categorisation has been approved by many irrigation management related projects. One such modification was followed in the Base Line Survey of Irrigation Commands, a Tamil Nadu Water Resources Consolidation Projects study incorporated by the Centre for Water Resources, Anna University, during the year 2000 and (Sophia \& Anuradha 2005).

According to the methodology, the marginal farmers are the individuals who hold less than 1 ha of land in the tank command area, small farmers hold 1 and 2 ha and the other farmers' category more than 2 ha of the irrigated plot. The sample was then selected from each subdivided classification utilizing probability proportional to size. Sample from head reach, middle reach and tail reach comes to were haphazardly chosen. The reality of random sampling is significant in light of the fact that it reflects assurance to attain findings that can be produced past the limits of the individuals who take an interest in the research. It allows one to demonstrate the probability that the result derived from the sample is likely to be found in the population from which the sample was taken. This is only possible if a random sample has been selected.

Total numbers of marginal, small and other farmers were collected from the Adangal Records in the study village and slightly more than $20 \%$ of them in each category were selected as respondents. Both men and women pattadhars were taken as respondents. The latter one was very meagre in number. Category wise, details of the total number of farmers in the selected study village and the selected sample with percentage are provided in Table 1.
Table 1: Reach-wise distribution of sample farmers in the study village.

\begin{tabular}{|lllll|}
\hline S1. & Farmer's & Pelasur Village & & \\
\cline { 3 - 5 } & & $\begin{array}{l}\text { Total number of } \\
\text { farmers }\end{array}$ & $\begin{array}{l}\text { Sample } \\
\text { selected }\end{array}$ & Percentage \\
\hline 1. & Marginal & 50 & 14 & 28.00 \\
2. & Small & 74 & 22 & 29.70 \\
3. & Others & 287 & 66 & 22.30 \\
& Total & 411 & 102 & 24.81 \\
\hline
\end{tabular}

Since the present study also seeks to identify the impact of irrigation tank rehabilitation for together direct users and indirect users, it was decided that obtaining direct data straightforwardly from the respondents would be the most reliable sources through which the key focus of the study could be analysed. Despite the fact that the examination basically depends upon essential sources it still seeks data for some supportive and supplemental information, which are ancillary in nature (Long \& Grafton 2020). The secondary data were gathered from significant records such as land registration records (Adangal Registers), documentation from Government agencies, documents of different levels of Water Users Association and information and figures from Census documents. Village maps were collected from the Survey and Land Records department of the Government of Tamil Nadu.

\section{Tools of Data Collection}

So as to accomplish the proposed objectives, combinations of qualitative and quantitative techniques were utilized to assemble data. Impact of tank rehabilitation in some issues such as the number of seasons cultivated, changes in cropping patterns, sources of irrigation were addressed through a schedule. Though many questions were included in the interview schedule, other qualitative methods such as stakeholders' meetings and group discussions with certain categories of non-farm and off-farm involved villagers too added important information. The information drawn were analysed and presented in the respective sections.

The quantitative tool selected for the study was an interview method through which the required primary data were elicited from the respondents. Since the respondents constitute both literates and illiterates categories, the method adopted was found to be most appropriate. Interviews were held with 15 women and 178 men farmers in the study village. Interviews were conducted separately for the respondents and their responses were immediately noted in the schedule. There were some difficulties in the initial stages in getting information about the landholding size and income of the respondents but later when the purpose of the study was 
explained in detail the respondents felt free to give answers to all the statements incorporated in the schedule.

\section{MODULES OF QUESTIONNAIRE}

The interview began with questions identified with some segment attributes of the families and continued with family background. A detailed list of contents in seven parts of the schedule is given below:

- Bio-data of the respondents: Name, age, education, community, family size, occupation, livestock details and family background.

- Cropping pattern, land inheritance, the extent of land possessed (individual and family), size of operational holding and season wise crop raised in wet, dry and garden land.

- Season wise source of irrigation and reasons for the change in source during the post rehabilitation period, alternative source during the scarcity period.

- Land use and season wise type of crop cultivated, yield in bags or tons, input and output cost per ha of land.

- Groundwater usage: Number of wells, type of wells, energy used, horsepower, depth of well, depth of water table, frequency and duration of pumping groundwater, local water market, well expenses and conjunctive use.

- Type and source of irrigation in different stages of crop growth, number of well and tank irrigation and sufficiency of irrigated water in the field.

- Total expenses for the land possessed by the respondents including, seed, nursery, transplantation, fertilisers, weeding, harvest and transportation cost.

\section{Audio and Video Recording}

Interviews were conducted with landholding farmers, landless poor, women and other vulnerable groups. The entire proceedings were recorded in a tape recorder and a hand camera. This helped to retrieve the material and analyse as and when new thoughts generate about the type of analysis. This is an added improvement due to the availability of electronic equipment.

\section{Data Analysis}

The information subsequently acquired were the first master tabulated in Microsoft Excel sheet using suitable coding and the variables for incorporation in the analysis were chosen and transferred into raw data files. Further, it was organized into SPSS-23.0 files for analysis which in certainty proved to be a necessary part of the research. Appropriate data analysis was carried and for simplicity and practical usefulness, only limited but more useful tools such as simple frequency and percentage table, and cross tables were used. The key objective of frequency distribution and percentage table was to summarise the comprehensive information. Cross tabulation is a procedure of Bivariate analysis, which is one of the modest and most commonly used ways for investigating the connection between at least two factors. Since this study concentrates on tank users both before and after its rehabilitation period, comparative analysis like Paired-samples t-test (which is a compare means analysis) in SPSS was taken into consideration.

\section{Paired Sample $t$-test}

The paired samples t-test compares the means of two variables. It computes the differences between two variables for each case and tests to see if the average difference is significantly different from zero (Pham \& Jimenez 2012, Constance \& Cribbie 2012). The observed data were from the same subject or a matched subject and were drawn from a population with a normal distribution. Subjects are often tested in a before-after situation (across time, with some intervention occurring such as tank rehabilitation). The paired t-test is actually a test where the differences between the two observations are 0 . So, if $D$ represents the difference between observations, the hypotheses are:

$\mathrm{H}_{\mathrm{o}}: D=0$ (the difference between the two observations is 0 )

$\mathrm{H}_{\mathrm{a}}: D \neq 0$ (the difference is not 0 )

The test statistic is $t$ with n-1 degrees of freedom. If the $\mathrm{p}$-value associated with $\mathrm{t}$ is low $(<0.05)$, there is evidence to reject the null hypothesis. Thus, one would have evidence that there is a difference in means across the paired observations.

Hence, this is an ideal test to study the impact of rehabilitation in two different tanks during pre and post-rehabilitation periods.

\section{RESULTS AND DISCUSSION}

\section{Season wise Area Cultivated in Wetland before and after Rehabilitation by Pelasur Respondents}

Table 2 and Fig. 1 clearly explicate the increase in total wetland cultivated area in the post rehabilitation period. There is a reduction in first and second season paddy cultivation, which is compensated by a drastic increase in annual crop cultivation. Availability of assured water supply throughout the year for irrigation either through surface or subsurface sources is the major reason for the change in cropping pattern. This indicates the positive impact of tank 
rehabilitation in Pelasur village. Also, there is an increase of 9 ha area of cultivation in the third season paddy crop during the post-rehabilitation period. Paddy is overpriced in the third season while marketing, labour cost is low due to surpluslabour availability and easy availability of fertiliser may be the reasons for increased third season paddy cultivation. Area cultivated during the third season is very low when compared to the total cultivated area and hence the availability of labour and fertiliser is high. Since the climate is hot, pesticide and rat problems are low in the third season when compared to the first and second seasons.

The output presented in Table 3 confirms the outcome that a significant positive relationship exists between the total area cultivated in wetland and the tank rehabilitation $(\mathrm{r}=0.866, \mathrm{p}<0.05)$. Therefore, the increased total area cultivated in the wetland during the first season is highly related to tank rehabilitation.

Observations in Table 4 related to the total area cultivated in the tank command area before and after the tank rehabilitation were randomly assigned to confirm that responses are due to the tank rehabilitation and not due to other factors. Paired t-test technique was used to test the null hypothesis and contrast the outcomes to demonstrate that there is a distinction between the total area cultivated before and after the tank rehabilitation.

The analysis output reveals that there is no difference between the total area cultivated by the respondents in pre and post-rehabilitation periods. Tank rehabilitation does not significantly improve the area cultivated in the wetland during the first season, $\mathrm{t}(101)=0.520, \mathrm{p}>0.05$. Hence, it is

Table 2: Season wise area cultivated in wetland before and after rehabilitation by Pelasur respondents.

\begin{tabular}{|lllll|}
\hline S1. no. & Description & $\begin{array}{l}\text { Area cultivated before rehabilitation } \\
\text { (ha) }\end{array}$ & $\begin{array}{l}\text { Area cultivated after rehabilitation } \\
\text { (ha) }\end{array}$ & $\begin{array}{l}\text { Difference } \\
\text { (ha) }\end{array}$ \\
\hline 1 & Total cultivated area & 138.28 & 162.92 & 24.65 \\
2 & First season & 46.14 & 39.95 & -6.19 \\
3 & Second season & 43.79 & 28.49 & -15.30 \\
4 & Third season & 4.13 & 12.57 & 8.45 \\
5 & Annual crop & 44.21 & 81.91 & 37.70 \\
\hline
\end{tabular}

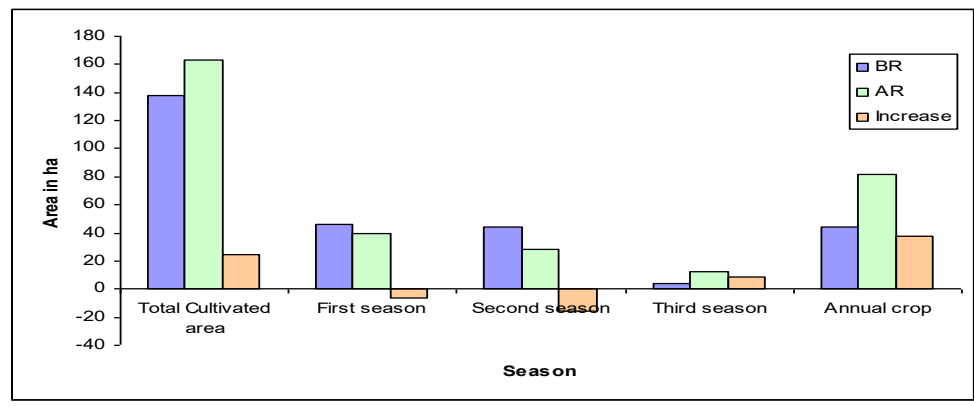

Fig.1: Season wise area cultivated in wetland before and after rehabilitation by Pelasur respondents.

Table 3: Paired samples correlations for first season wetland before and after rehabilitation by Pelasur respondents.

\begin{tabular}{|llll|}
\hline Description & Number of total respondents & Correlation & Sig. \\
\hline Pair 1 & $\begin{array}{l}\text { Wetland cultivable area first season before rehabilitation and Wetland } \\
\text { cultivable area first season after rehabilitation }\end{array}$ & 102 & 0.866 \\
\hline
\end{tabular}

Table 4: Paired samples t-test for first season wetland before and after rehabilitation by Pelasur respondents.

\begin{tabular}{|c|c|c|c|c|c|c|c|c|c|}
\hline \multicolumn{2}{|c|}{ Description } & \multicolumn{5}{|c|}{ Paired Differences } & \multirow[t]{3}{*}{$\mathrm{T}$} & \multirow[t]{3}{*}{ df } & \multirow{3}{*}{$\begin{array}{l}\text { Sig. } \\
\text { (2-tailed) }\end{array}$} \\
\hline & & \multirow{2}{*}{ Mean } & \multirow{2}{*}{$\begin{array}{l}\text { Std. } \\
\text { deviation }\end{array}$} & \multirow{2}{*}{$\begin{array}{l}\text { Std. error } \\
\text { mean }\end{array}$} & \multicolumn{2}{|c|}{$95 \%$ confidence interval of the difference } & & & \\
\hline & & & & & Lower & Upper & & & \\
\hline Pair 1 & $\begin{array}{l}\text { Wetland cultivable area } \\
\text { first season before reha- } \\
\text { bilitation and wetland } \\
\text { cultivable area first sea- } \\
\text { son after rehabilitation }\end{array}$ & -0.060 & 1.179 & 0.116 & -0.292 & 0.171 & -0.520 & 101 & 0.604 \\
\hline
\end{tabular}


concluded that the area cultivated in the post-rehabilitation period is highly correlated with the tank rehabilitation but does not show significant change during the first season of paddy cultivation.

The output presented in Table 5 confirms the result that a significant positive relationship exists between total area cultivated with annual crop (sugarcane) in wetland and tank rehabilitation $(\mathrm{r}=0.651, \mathrm{p}<0.05)$. Therefore, an increased total area cultivated with annual crop (sugarcane) in wetland is associated with tank rehabilitation.

To test the null hypothesis of no difference between total area cultivated during pre and post-rehabilitation periods, paired t-test was used to compare the results. As can be seen from the output presented in Table 6, a significant difference exists between the total area cultivated with annual crop (sugarcane) in wetland by the respondents in pre and post-rehabilitation periods. Tank rehabilitation significantly improves the total area cultivated with annual crop (sugarcane) in wetland, $\mathrm{t}(101)=5.379, \mathrm{p}<0.05$

\section{Season wise Crops Cultivated in Wetland before and after Rehabilitation by Pelasur Respondents}

Table 7 portraits the percentage of respondents cultivating crops in wetland before and after the tank rehabilitation. It is clear that before rehabilitation $52 \%$ of the total respondents cultivated paddy as their first season crop (i.e. from June to September), which was reduced to $42 \%$ now. Even though the data show that wetland respondents are not cultivating groundnut in the command area, it is not the case in the overall scenario. Cultivating groundnut in wetlands by the well-owing farmers in the third season is in practice and the reason enlightened by them is that it provides good green manure for succeeding paddy crop which increases the yield/ ha. Being a legume crop, groundnut can fix the atmospheric nitrogen and thereby improve soil fertility.

Cultivating groundnut with well water is practised both in wetland as well as in garden land. Cultivating groundnut as the first crop in wetland is not in practice both before and after the rehabilitation in Pelasur. Since summer season (third season) is the suitable period for groundnut cultivation, whereas $1 \%$ of the total respondents before rehabilitation and $2 \%$ after rehabilitation cultivate groundnut as a second crop. Those two respondents have oil extraction machine and doing oil selling business along with agriculture. Around $41.2 \%$ of the total respondents were cultivated paddy as the second crop and this is reduced to $35.3 \%$ during the postrehabilitation period. The increased water table in command area wells helps in increased third season cultivation from $4.9 \%$ to $13.7 \%$ in the post-rehabilitation period. Sugarcane crop scenario shows an incredibly positive impact of tank

Table 5: Paired sample correlations for annual crop cultivated in wetland before and after rehabilitation by Pelasur respondents.

\begin{tabular}{|llll|}
\hline Description & N & Correlation \\
\hline Pair 1 & $\begin{array}{l}\text { Wetland cultivable area annual before rehabilitation and wetland cultivable area } \\
\text { annual after rehabilitation }\end{array}$ & 102 & 0.651 \\
\hline
\end{tabular}

Table 6: Paired sample t-test for annual crop cultivated in wetland before and after rehabilitation by Pelasur respondents

\begin{tabular}{|c|c|c|c|c|c|c|c|c|c|}
\hline \multicolumn{2}{|c|}{ Description } & \multicolumn{5}{|c|}{ Paired Differences } & \multirow[t]{3}{*}{$\mathrm{T}$} & \multirow[t]{3}{*}{$\mathrm{df}$} & \multirow{3}{*}{$\begin{array}{l}\text { Sig. } \\
\text { (2-tailed) }\end{array}$} \\
\hline & & \multirow[t]{2}{*}{ Mean } & \multirow[t]{2}{*}{$\begin{array}{l}\text { Std. } \\
\text { deviation }\end{array}$} & \multirow[t]{2}{*}{$\begin{array}{l}\text { Std. error } \\
\text { mean }\end{array}$} & \multicolumn{2}{|c|}{$\begin{array}{l}95 \% \text { confidence interval of the } \\
\text { difference }\end{array}$} & & & \\
\hline & & & & & Lower & Upper & & & \\
\hline Pair 1 & $\begin{array}{l}\text { Wetland cultivable area } \\
\text { annual before rehabilitation } \\
\text { and wetland cultivable area } \\
\text { annual after rehabilitation }\end{array}$ & -0.912 & 1.714 & 0.169 & -1.249 & -0.576 & -5.379 & 101 & 0.000 \\
\hline
\end{tabular}

Table 7: Season wise crops cultivated in wetland before and after rehabilitation by Pelasur respondents

\begin{tabular}{|c|c|c|c|c|c|c|c|c|c|}
\hline \multirow[t]{4}{*}{ S1. no } & \multirow[t]{4}{*}{ Season } & \multicolumn{8}{|c|}{ Percentage of respondents } \\
\hline & & \multicolumn{4}{|c|}{ Before rehabilitation } & \multicolumn{4}{|c|}{ After rehabilitation } \\
\hline & & Paddy & Groundnut & Sugarcane & None & Paddy & Groundnut & Sugarcane & None \\
\hline & & $\%$ & $\%$ & $\%$ & $\%$ & $\%$ & $\%$ & $\%$ & $\%$ \\
\hline 1 & First season & 52 & 0 & 0 & 47.1 & 42 & 0 & 0 & 55.9 \\
\hline 2 & Second season & 41 & 1 & 0 & 57.8 & 35 & 2 & 0 & 62.7 \\
\hline 3 & Third season & 4.9 & 0 & 0 & 95.1 & 14 & 1 & 0 & 85.3 \\
\hline 4 & Annual & 0 & 0 & 30.4 & 69.6 & 0 & 0 & 54.9 & 45.1 \\
\hline
\end{tabular}


rehabilitation through the increased cultivated area from $30 \%$ to $55 \%$ after the rehabilitation.

Hence, the overall circumstances show that even though the paddy cultivation area was reduced during the post-rehabilitation period, there is a significant increase in the sugarcane cultivation area in Pelasur. Availability of a farm road facility till the tail reach for loading and unloading sugarcane is the key reason reported by the farmers. Earlier it was very difficult for the tail reach farmers to transfer the produce from the field. Transporting sugarcane bundles from the field to the main road leading to more number of labours and labour charge. Now with the availability of a farm road, farmers can bring bundles easily through small carts to the place where trucks are ready to take sugarcane to the sugar mill. Also, farmers who are engaged in some other occupation had gone for sugarcane cultivation, since it is not necessary to take much care on sugarcane crop during the growth stage as in the case of paddy crop. Consequently, farmers like to develop crops that require less close to individual responsiveness. Paddy being a short duration seasonal crop requires less attention in spite of its varieties (Reddy et al. 2008). Guaranteed water supply during the time is additionally a fundamental purpose behind the cropping change.

Respondents quoted that sugarcane is a cash crop and has a constant market rate. i.e. rate/ton does not vary with respect to market surplus or scarcity. Moreover, the rate/ton keeps on increasing with time and never decreases. For paddy, there are ups and downs in rate/bag even within the season itself and with respect to market surplus and scarcity. Another reason cited by respondents is that problem caused by rats is less in sugarcane when compared to paddy which leads to a reduction in yield/ha. Tail reach soil is more suitable for cultivating sugarcane than paddy due to its slight salinity nature. Sugarcane can withstand mild flood and drought to some extent when compared to paddy. This tempts farmers in Pelasur village to cultivate sugarcane as their major crop. Very few farmers are cultivating sugarcane three times (i.e. 3 years) continuously and paddy for the fourth year. The peculiar reason attributed is the changing cropping pattern at regular intervals of time, which might help to make up the soil nutritious and increase the yield of both the crops. Further, changes in the cropping pattern from paddy to sugarcane in the neighbouring field induce farmers to adopt the same after they are aware of the income incurred by sugarcane cultivators. In future, sugarcane cultivation is relied upon to build more with innovative changes, for example, the spread of high yielding crop varieties, harvesting techniques, utilization of pesticides, insecticides and composts, mechanization of farm work, lack of capable workers for paddy cultivation and so forth. Hence, farmers feel that cultivating sugarcane is more profitable than paddy. Help from sugar mill (by providing crop insurance, loan for initial investment, lending fertiliser at right time at desirable cost, arranging mini contract labours for sugarcane cutting etc.,) tempts farmers in Pelasur to change cropping pattern from paddy to sugarcane.

\section{CONCLUSION}

The main objective of tank rehabilitation is to alleviate poverty and raise the standard of living of the small and marginal farmers in the rural areas who have access to a large irrigation system. There is an increase of 9 ha area of cultivation in the third season paddy crop during the postrehabilitation period. Around $41.2 \%$ of the total respondents have cultivated paddy as a second crop and this is reduced to $35.3 \%$ during the post-rehabilitation period. But sugarcane crop scenario shows an incredibly positive impact of tank rehabilitation through the increased cultivated area from $30 \%$ to $55 \%$ after the rehabilitation. Many farmers shifted from paddy cultivation to sugarcane since it is a cash crop. Paired sample t-test result shows that there is an increase in the total area cultivated is highly associated with tank rehabilitation. Hence equal importance should be given to both tank infrastructure and command area development for enhancing agricultural productivity. Hence, a tank as a common property resource can be protected and kept sustainable for long periods.

\section{REFERENCES}

Adams, W. M. 1989. Definition and development in African indigenous irrigation. Journal of Azania: Archaeological Research in Africa, 24(1): 21-27.

Agarwal, A. and Narain, S. 2003. Dying Wisdom. Centre for Science and Environment, New Delhi.

Anuradha, B. 2008. Impact of rehabilitation of tanks in peri-urban areas. 20th International Congress in Irrigation and Drainage, Lahore, 112.

Anuradha, B. and Ambujam, N.K. 2011. Impact of irrigation tank rehabilitation on garden land agriculture - a case study in rural village of Tamilnadu. International Journal of Agricultural and Statistical Sciences, 7(2): 493-498.

Aubriot, O. and Prabhakar, P. I. 2011. Water institutions and the 'revival of tanks' in South India: What is at stake locally? Water Alternatives, 4(3): 325-346.

Balamurugan, P. 2013. Rural tanks and their modernisation for sustainable rural development. International Conference Proceedings-I, Annamalai University, Annamalainagar.

Chattopadhyaya, S. 2003. Scarcity admist plenty: A study on tanks of Kerala state. In: Tanks of South India, (Ed). Centre for Science and Environment, NewDelhi.

Chiranjeevalu, P. 1988. Tank Irrigation and Agricultural Development. Kanishka Publishing House, NewDelhi.

Constance, A. Mara and Robert A. Cribbie 2012. Paired-samples tests of equivalence. Communications in Statistics. Simulation and Computation, 41(10): 1928-1943. 
Dharmasena P.B. 2019. Agricultural research for sustainable food systems in Sri Lanka: volume 1: a historical perspective. Springer Nature Singapore Pte Ltd Cascaded Tank-Village System: Present Status and Prospects.

Easter, W. 1997. Tank Development: The North Eastern Thailand Experience. Anna University, Chennai.

Fischer, A., Tadesse, D., Weldesemaet, Y. T. and Ashenafi, Z. T. 2014. On the interplay of actors in the co-management of natural resources-A dynamic perspective. World Development, 64: 158-168.

Govindaiah, T. 1992. Tank rehabilitation and integrated rural development. Institute of Research in Social Sciences, Bangalore.

Jagger, P., Sellers, S., Kittner, Das, I. and Bush, G. K. 2018. Looking for medium-term conservation and development impacts of community management agreements in Uganda's Rwenzori Mountains National Park. Ecological Economics, 52: 199-206.

Jana, S. K., Palanisami, K. and Das, A. 2012. Prospect of sustainable tank irrigation option in the dry zones of West Bengal. Indian Journal of Agricultural Economics, 67(2): 225-37.

Khandker, V., Gandhi, V.P. and Johnson, N. 2020. Gender perspective in water management: the involvement of women in participatory water institutions of eastern India. Water, 12(196): 1-20.

Kiran Kumara, T. M., Shiv Kumar, Dharam Raj Singh and Kingsly Immanuelraj 2018. Participation in community based tank irrigation system in a rainfed region of India. Indian Journal of Agricultural Sciences, 88(4): 596-600.

Long C. R. and Grafton, Q. 2020. Water pricing and the value-add of irrigation water in Vietnam: Insights from a crop choice model fitted to a National household survey. Agricultural Water Management, 228: $1-8$.

Meinzen-Dick, R. 2007. Beyond panaceas in water institutions. Proceedings of the National Academy of Sciences, 104(39): 15200-15205.

Narayanamoorthy, M. A. 2007. Tank irrigation in India: A time series analysis. Water Policy, 9 (2): 193-216.

Naru, S. and Jana, S.K. 2017. A Study on Tank Irrigation Productivity in Saline Zone of South 24 Parganas. Vidyasagar University, Midnapore Sebak Kumar Jana University.

Palanisamy, K. and Easter, W. 2010. Small scale surface tank irrigation in Asia. Water Resources Research, 33(2).

Persha, L., Agrawal, A. and Chhatre, A. 2011. Social and ecological synergy: Local rulemaking, forest livelihoods, and biodiversity conservation. Science, 331: 1606-1608.
Reddy, V.R., Reddy, M.G., Reddy, Y.V. and Soussan, J. 2008. Sustaining rural livelihoods in fragile environments. Resource endowments and policy interventions-A study in the context of participatory watershed development in Andhra Pradesh. Indian Journal of Agricultural Economics, 63(2): 69-187.

Sakthivadivel, R. 2005. Two decades of tank rehabilitation in India: Investment institutional and policy issues. IWMI, Tata water policy research program, and annual partners meet, Anand.

Sengupta, N. 1985. Irrigation-traditional vs. modern. Economic and Political Weekly, 20 (45): 1919-1938.

Shah, M. 2009. Participatory watershed development: An institutional framework. (In) Making Water everybody's Business. Agarwal A, Khurana I and Narain S (Eds). Centre for Science and Environment, New Delhi.

Shah, Manisha and Sakthivadivel, Ramaswamy 2018. Will Kudimaramathu make communities "think tanks" again? International Journal of Engineering and Technology, 7 (4): 6878-6883.

Shah, T. 1998. Water against poverty: livelihood-oriented water resource management. Water Nepal, 6(1): 117-143.

Shah, T. and Raju, V. 1988. Groundwater markets and small farmer's development. Economic and Political Weekly, 26: 23-28.

Singh, A.K. 2004. Impact of watershed development in traditional tank systems: a caste study. Journal of Rural Development, 33(1).

Sivasubramaniam, K. 2006. Sustainable development of small water bodies in Tamilnadu. Economic and Political, 2: 2854-2863.

Sophia, J.D. and Anuradha, B. 2005. Two decades of tank rehabilitation in India: Investment institutional and policy issues. IWMI, Tata Water Policy Research Program and Annual Partners Meet, Anand.

Sowbi, R.B. and Sabarish, A.K.V. 2017. A review- tank and its role in recharging groundwater. International Journal of Civil Engineering and Technology (IJCIET), 8(10): 207-212,

Thang, V. Pham and Connie, R. Jimenez 2012. An accurate paired sample test for count data. ECCB, 28: 596-602.

Vaidyanathan, A. 2003. Tanks of South India. Centre for Science and Environment, NewDelhi.

Vaidyanathan, A. 2006. India's Water Resources: Contemporary Issues of Irrigation. Oxford University Press, New Delhi.

Welgama, N.K.K. and Wanigasunder, W.A.D.P. 2012. The impact of rehabilitation approaches in the sustainability of the management of small tanks in Sri Lanka. International Journal of Economics and Management Engineering, 6(12): 3745-3753. 